\title{
Perceiving education from Facebook profile pictures
}

\section{Michael V. Reiss}

University of Zurich, Switzerland

\section{Milena Tsvetkova}

London School of Economics and Political Science, UK

\begin{abstract}
Our upbringing and education influence not only how we present and distinguish ourselves in the social world but also how we perceive others. We apply this central sociological idea to the social media context. We conduct a large-scale online study to investigate whether observers can correctly guess the education of others from their Facebook profile pictures. Using the binomial test and cross-classified mixed effects models we show that observers can assess the education of depicted persons better than chance, especially when they share the same educational background and have experience with the social media. We also find that posting pictures of outdoors activities is a strong signal of having higher education, while professional photographs can obscure education signals. The findings expand our knowledge of social interaction and self-expression online and offer new insights for understanding social influence on social media.
\end{abstract}

\section{Keywords}

social media, Facebook, self-presentation, perception, social class, habitus, Bourdieu, photographs, digital inequalities

\section{Introduction}

On social media platforms and especially social network sites such as Facebook, Instagram, Tinder, and Snapchat, pictures have become major vehicles of self-disclosure and self-expression, as well as central objects of communication and interaction (Van Dijck 2008; Zhao et al. 2008; Hancock and Toma 2009; Winston 2013; Kapidzic and Herring 2015; Ward 2017). Profile pictures, in particular,

\section{Corresponding author:}

Michael V. Reiss, Department of Communication and Media Research, University of Zurich, Andreasstrasse 15, 8050 Zurich, Switzerland.

Email: m.reiss@ikmz.uzh.ch 
play a pivotal role, functioning as an important identifier of the user and "central component of online self-presentation" (Hum et al. 2011: p. 1828). On Facebook, for example, with more than two billion users the world's largest social network site (Facebook 2019), the profile picture is visible to all other Facebook users, no matter how strict the person's privacy settings are. In addition, the profile picture is shown next to every interaction that users do or did on the platform. Therefore, the profile picture constitutes both the best and most important instrument for Facebook users to shape and convey a certain self-image. In parallel, from the observer's perspective, the profile picture is most relevant and visible to form perceptions about other Facebook users. In fact, Facebook profile pictures have been shown to affect interactions even outside the platform, such as recruiters' decision whether to invite a job candidate for an interview (Baert 2018).

Profile pictures loom particularly consequential in light of the large amount of information that we seem to be able to extract from photographs of individuals (Todorov et al. 2015). Previous research has shown that we can predict a person's personality traits such as narcissism (Kapidzic 2013; Wu et al. 2015) and extraversion, neuroticism, agreeableness, conscientiousness, and openness (Liu et al. 2016; Segalin et al. 2017) from their social media profile picture. How a person presents themselves in the photograph can influence our judgement of that person's competence and trustworthiness (Etcoff et al. 2011). Further, photographs convey enough information to help us, sometimes aided by machines, guess better than chance a person's sexual orientation (Wang and Kosinski 2018), political affiliation (Rule and Ambady 2010), their criminality and corruptibility (Valla et al. 2011; Lin et al. 2018), their intelligence (Kleisner et al. 2014), their likelihood to win an election if they are a political candidate (Todorov et al. 2005), and even their likelihood to receive the death penalty if they are a convicted murderer (Wilson and Rule 2015).

Much of the research on construing social attributes from faces comes from psychology and focuses on biological, evolutionary, and cognitive theoretical explanations. This research has shown that we base our judgements on physical features of adaptive significance such as masculinity or femininity, on emotional expressions such as smiling, as well as on non-perceptual factors related to cultural context (for example, how typical a face is) and personal experience (whether the face is familiar) (Todorov et al. 2015). The most prominent explanation for this behavior is the overgeneralisation hypothesis - we have evolved and adapted to read fitness, emotion, and familiarity in faces and we associate this information with certain qualities but we also tend to attribute these qualities to people whose faces merely resemble them (Oosterhof and Todorov 2008; Zebrowitz and Montepare 2008). A more radical explanation rests on the essentialist assumption that recognizable biological markers for homosexuality, criminality, intelligence, etc. exist (Haselhuhn and Wong 2011; Wang and Kosinski 2018). These theoretical perspectives, however, are both limited in the same way they approach social perception as an individual cognitive process. An alternative perspective is that our social perceptions are socially constructed (Bourdieu 1990; Berger and Luckmann 1991). We have developed a shared understanding of how, for example, a homosexual, a gangster, or an intellectual look like and we present ourselves and read others according to these ideas. In essence, the observer and the observed form a social system in which shared meanings are communicated. Even subtle clues such as image quality, facial expression, grooming, or eyeware can be vehicles for 
self-presentation and social signaling (Agüera y Arcas et al. 2018). This study aims to capture these ideas both theoretically and empirically.

In this study, we investigate whether individuals can correctly identify a person's education from their Facebook profile pictures. We focus on education as a core element of habitus. The concept of habitus represents the system of dispositions and orientations that shapes how we perceive the social world and how we act in it (Bourdieu 1984). Our upbringing and social environment determine our habitus and our habitus determines how we express ourselves and how we perceive the selfexpression of others. We use a large online survey with US residents to investigate how social similarity, higher perceptiveness, stereotypes, and specific habitus signals affect an individual's ability to correctly guess Facebook users' education from their profile pictures.

Our work contributes to the growing body of research centering on socio-demographic factors and aspects of class in the online context. Previous work has investigated differences in the internet and social media use related to social status, age, education, taste, or social capital (Liu 2008; Hargittai and Hinnant 2008; Pfeil et al. 2009; Zillien and Hargittai 2009; Junco 2013; Büchi et al. 2016). Some studies explicitly apply Bourdieusian concepts (Robinson 2009; Lutz 2016; Yates and Lockley 2018). Most of the previous research, however, focuses on only one side of the problem - how social factors affect online engagement and self-presentation. We introduce the flip side - how social factors affect the perception of online content and personas - and use Bourdieu's habitus theory to capture the interplay between the two.

The extent to which we can correctly judge another person's education from their online pictures has important implications for social influence, trust, discrimination, and bias online and in general. For example, information and opinions often spread on Facebook via posts by friends of friends. Consciously or not, we form impressions from the profile pictures accompanying these posts and these impressions can affect how we act upon new information. We are more likely to adopt behaviors and trust information from those who are more similar to ourselves (McPherson et al. 2001; Rogers 2010) and we consume and believe news better when we trust the sender (Turcotte et al. 2015), so recognizing our habitus in others could increase their influence over us. Similarly, we are prone to defer to individuals of higher social status and authority (Correll and Ridgeway 2003; Cialdini 2007), so judging someone to have more education and knowledge than ourselves places them in a position of power. Conversely, not recognizing signs of a habitus a person claims to possess could decrease that person's credibility, such as in the anecdotal case of potential employers stumbling upon job candidates' drunk photos online.

\section{Theoretical Background and Hypotheses}

Already Veblen (2007 [1899]) brought forward that people engage in strategic dressing and clothing to demonstrate their social status to others. In addition, Goffman (1956) suggested that people carefully shape the desired representation of themselves and are interested in a certain perception by others. Following on those ideas, Bourdieu (1984) demonstrated both theoretically and empirically 
that the way people act, what they think, and how they perceive the world are heavily shaped by their own and their parents' endowment of capital. Depending on economic, cultural, and social capital people develop a certain habitus. The habitus represents the sense of orientation towards the social world - it generates social practices and evaluates and interprets them. In fact, as both a product and a producer of practices, the habitus can be understood as two sides of the same coin. As a result of people's social surrounding - their upbringing, parents, school, etc. - they establish a certain habitus and exert practices accordingly. Similar socio-economic and cultural preconditions, therefore, lead to a comparable habitus and similar practices. These practices become concretely visible in the tastes of people and constitute the empirical manifestation of the habitus in everyday life. It is, therefore, the habitus that both determines how individuals express themselves and how individuals perceive the self-expressions of others.

Bourdieu suggests that people almost always deploy strategies of distinction in their social actions. The habitus is inextricably tied to the actor and therefore, effective in all actions. Referring back to Leibniz, Bourdieu (1984: p. 474) states "we are automatons in three-quarters of what we do". Thus, taking and choosing a profile photograph is an act of embodied history and, even in its spontaneity and without consciousness, a strategic and distinctive one (Bourdieu 1990). This statement is mirrored by Bourdieu's claim that people can perceive manifestations of the habitus and related strategies of distinction in everyday life. As a social being, one roughly knows their own place in society and the positions below and above. People are socialized to recognize and interpret strategies of distinctions because one's "social identity is defined and asserted through difference" (Bourdieu 1984: p. 172).

This difference also crystallizes in and through education. As a form of cultural capital, education is fundamental for habitus formation. For the US it has been shown that students' habitus, as defined by childhood socialization, influences success in the education system (Dumais 2002) but also that school context significantly impacts students' habitus as well (Horvat and Davis 2011; Lehmann 2013). Whether acting as a conservative force, bolstering existing class differences (Bourdieu 1974), or as a mechanism for social mobility, education is decisive for the habitus. Furthermore, education holds implications beyond this direct relation. As a form of cultural capital, education is of exchange value and convertible into other forms of capital (Bourdieu 1986). Education dictates income, molds cultural knowledge, and defines social circles. Consequently, education and habitus are strongly interlinked: having or not having certain education makes a difference in people's habitus that manifests itself in perceptible daily and distinct practices. Transferred to the observation of Facebook profile pictures, this leads to the following hypothesis:

\section{H1: Observers can assess a person's education better than chance.}

\section{Perceptiveness}

Observers with more astute perceptiveness will be better at discerning a person's habitus. On the one hand, homogeneity in socialization between the observer and the observed individual, should enhance the observer's ability to recognize subtle strategies of distinction and to correctly identify 
taste styles (Bourdieu 1977). Similarity along visible demographic characteristics such as age, gender, race, and ethnicity could additionally hone one's recognition of whether a person has a similar or different habitus. In essence, we expect that homophily along these social characteristics would have made individuals more familiar with and sensitive to differences in other aspects. In our context, this leads us with:

H2: Observers who are similar to the depicted person in education, age, gender, race, and ethnicity are more likely to assess a person's education correctly.

On the other hand, some individuals may be more perceptive than others. Bourdieu argues that the lower social class (i.e. individuals with low education and low income) do not have the habitual ability to reflect their own situation or the social structure (Bourdieu 1984). Hence, it is likely that observers with higher education perform better in assessing education than observers without because only the more sophisticated habitus allows to reflect about potential strategies of distinction and concrete taste representations. Observers with greater exposure to diverse social classes and lifestyles and with more sophisticated knowledge of the particular medium are also expected to be more perceptive and discerning.

H3: Observers with higher education, who live in an urban setting, and who are Facebook users are more likely to assess a person's education correctly.

\section{Self-presentation}

An observer will be better at discerning a person's habitus if the observer is more perceptive, but also if the habitus signal is louder and clearer. Photographs constitute a condensed and expressive image of one's habitus. Bourdieu himself used many photographs in his Distinction to support his analysis on the habitus and display noteworthy (or typical) manifestations (ibid.). When seeing the habitus as an embodied generative principle, a picture is a product of that generative principle and captures and illuminates aspects of the habitus that "cannot even be made explicit" (Bourdieu 1977: p. 94).

Since habitus crosscuts the different forms of capital, it can reveal itself in photographs in many different ways. The appearance, activity, and social setting of a person in a photograph may contain both obvious economic markers and subtle cultural clues. In contrast to the accentuated taste stratification and classification identified and introduced by Bourdieu, it has been shown that, in the US, individuals of higher social status tend to be "cultural omnivores", espousing broader and more eclectic cultural tastes (Peterson 1992; Holt 1998). This make it difficult to theorize about how capital endowment translates into specific practices without starting from empirical observations. The few recent empirical studies on this topic, however, are too context-specific to be informative for online social media in general (Johnston and Baumann 2007; West 2010). Nevertheless, we can still rely on general assumptions from Bourdieu to form expectations about profile pictures. For example, being photographed on the background of the Easter Island statues would suggest higher education because the depicted person has both the economic capital to travel and the interest and open mindedness to explore new cultures. Hiking on the hills, on the other hand, is not necessarily 
an expensive activity but may still be indicative of higher education if it has become associated with appreciation for natural beauty and concern for health and the environment.

Social media profile pictures have the additional feature of being user-generated or at least userselected. On the one hand, this implies a more immediate habitus-picture relation for the given individual, since interference by other parties can usually be precluded. On the other hand, however, the individual could also use their profile picture to strategically misrepresent their habitus. For example, an individual could choose to wear glasses with clear lenses, hoping that the stereotype that smart people wear glasses would skew others' perception of them. At the same time, it is also possible that despite one's self-presentation efforts, strong racial and gender stereotypes could distort the observer's judgment.

In general, whether unintentionally candid, strategically orchestrated, or incorrectly stereotyped, appearance, activity, and photographic style could all affect one's ability to correctly identify a person's habitus from their social media profile picture. Gray et al. (2011) and Daniels and Zurbriggen (2016) identified that persons dressed in a revealing or sexy way on photos are assessed to be less competent by observers. Corresponding to that, Hetsroni and Guldin (2017) found that people with lower education tend to use revealing pictures of themselves as a Facebook profile picture more often. In line with the common stereotype, studies "have consistently found that people who wear glasses are judged as being more intelligent" (Leder et al. 2011: p. 213). Pictures that are professionally photographed or manipulated in an obvious manner can similarly create a certain impression for the observer. For example, the phenomenon of selfie-styled self-portraits became increasingly popular in social media in recent years and has already been linked to personality (Qiu et al. 2015; Wang et al. 2017). Since it is difficult to anticipate the most common or distinctive self-presentation strategies in our context and the different ways in which they can be misleading or informative about a person's education, we will assume a more exploratory and data-driven approach:

H4: The clothing, activity, age, gender, race, and ethnicity of a person in a picture and the picture style and quality have non-zero effects on how likely an observer is to guess higher education and assess education correctly.

\section{Methods}

To test the hypotheses, we recruited a large number of participants from the online crowdsourcing platform Amazon Mechanical Turk (AMT) in summer 2018. AMT is a well established platform for social research that provides access to a large and diverse population and facilitates participant remuneration (Casler et al. 2013; Difallah et al. 2018; Buhrmester et al. 2018). To improve the homogeneity of the sample and the quality of the responses, we restricted our recruitment to adult US residents whose AMT user reputation is $95 \%$ or higher. We obtained two Facebook profile pictures from 112 of them and asked 713 others to guess whether the person in the pictures has a Bachelor degree or not. 


\section{Collecting Facebook profile pictures}

In a first stage, we screened for active Facebook users older than 23 who declared willingness to share their Facebook profile pictures. We included the age restriction to ensure that the participants have had the chance to complete higher education. Of all participants in this stage, $19.4 \%$ were either too young or did not have an active Facebook account. Of the remaining, 59.2\% decided not to share their profile pictures.

In a second stage, the pre-screened participants were invited to share their demographic information and upload two profile pictures. Because impressions based on a single image might not be fully accurate (Todorov and Porter 2014), we requested two pictures from each participant to increase the assessment reliability of observers. Furthermore, we requested that profile pictures are no older than two years and, mainly for ethical reasons, to depict only the participant and no other individuals. For most Facebook users this restriction should not have been a problem anyway (Strano 2008). Pictures showing a cartoon or landscape only were not allowed either. The final picture sample contains 224 profile pictures from 112 participants, half of whom have high school degree or lower and half higher education (Bachelor degree or higher).

\section{Collecting picture evaluations}

We conducted a separate AMT survey to collect observations on the profile pictures, taking care to exclude the participants who provided the pictures. After providing demographic information, each participant saw 37 pairs of pictures - one pair at a time - randomly selected out of the pool of 112 pairs. No additional information on the depicted person was provided. For each pair of profile pictures, participants had a binary choice to assess the educational background of the depicted person: Highschool degree or lower (e.g. no degree) and College degree or higher. Out of the 722 participants who completed the survey, eight were excluded because they failed to give proper consent and one participant was excluded for showing a uniform response pattern, leaving 713 in the final sample. In total, each of the 713 participants rated 37 pictures, leading to 26,381 observations. Each of the 112 pairs of pictures was evaluated on average 235.5 times.

The median response time per picture was $4.32 \mathrm{~s}$. Several studies demonstrate that a photo exposure of less than a second is sufficient for participants to form specific impressions and that longer periods of observation generally do not yield greater predictive accuracy (Ambady and Rosenthal 1992; Todorov et al. 2015). Moreover, empirical results in a similar setting show comparable observation times for photographs (Lawson et al. 2010). ${ }^{1}$

\section{Coding picture features}

We manually coded the collected profile pictures to identify prevalent patterns, features, and elements in each picture. We identified whether the depicted person is wearing eyeglasses, wearing revealing clothing such as underwear or a bathing suit, being outdoors, and doing sports, including hiking. We

\footnotetext{
${ }^{1}$ We tested a number of different strategies for excluding participants with too low survey duration but these did not result in significant changes with respect to the hypotheses investigated here. In addition, when included in the models, the effect of time per picture is not statistically different from zero.
} 
further identified whether the picture appeared to be shot by a professional photographer or camera, whether it was manipulated by adding a frame, cartoon elements, glitter, text, or a light filter, and whether it was a selfie. We also looked for obvious graduation signals such as a graduation gown or a doctor's coat but no picture from our sample included this feature. To enhance inter-coder reliability, three independent coders tagged the 112 pairs of pictures based on ex ante defined criteria. For all variables, Krippendorff's alpha was at least 0.82 (median 0.90), indicating a reasonable reliability (Krippendorff 2004). Conflicts were settled by majority ruling; no picture was excluded. Because there were two photos in each pair, pairs could either have zero, one, or two manifestations for each feature.

\section{Ethics}

All participants in this study gave informed consent on their participation and were informed in detail on the purpose of this study and the use of their data. To provide profile pictures, participants had to declare their willingness to do so at two separate events; for most participants at least 24 hours (often more) passed between both events. Furthermore, participants that provided pictures were informed on potential risks when sharing a profile picture (i.e. that study participants might identify them or their Facebook profile).

Since the use of AMT for commercial or scientific purposes has been criticized for exploiting workers on the platform as a cheap labor force (Gleibs 2017), we aimed for an ethical and fair remuneration of all study participants. In addition to a small remuneration for the first stage, those who provided profile pictures received $\$ 1$ for their participation in the second stage. Considering the median survey completion time (289 seconds), this results in a median hourly wage of $\$ 12.50$, which exceeds both the federal minimum hourly wage in the US and the average remuneration for workers on the AMT platform (Hara et al. 2018). With a median time of 338 seconds, the participants assessing the pictures were slower than we calculated in the pilot test. Those participants received a median hourly wage of $\$ 6.40$, failing to achieve the federal minimum wage of $\$ 7.25$ but still above the AMT average.

\section{Analytical strategy}

The main dependent variable is binary, indicating whether the observer's assessment of the education of the person in the picture is correct. Since the sample is balanced with respect to the education of the depicted persons, the chance of correctly guessing the education is 0.5 . Furthermore, since the task is the same for all observers, the aggregated proportion of success $\pi$ can be tested against the expected success rate if guessing was done completely at random, namely 0.5 . Therefore, for $\mathrm{H} 1$, we can use a binomial test on $\pi$ to reveal whether observers can assess the education of the depicted persons better than chance. This will be supplemented with the result from an intercept-only crossclassified logistic mixed effects model giving the proportion of successful guesses when controlling 
for the heterogeneous correlation structure of the data, i.e. controlling for both observer-level and picture-level effects. $^{2}$

We use two cross-classified logistic mixed effects models to test the remaining hypotheses. In the first model, we predict the likelihood to correctly guess the depicted person's education. For H2, we test for the effects of similarity in education, age, gender, and race between the observer and the depicted person, for H3 - observer's education, Facebook activity, and urban residence, and for H4 - the coded picture features and the depicted person's age, gender, and race, while controlling for relevant demographics of the observer. We use the following random-intercept model for success $\pi$ :

$$
\operatorname{logit}\left(\pi_{i j}\right)=\beta_{0}+\alpha X_{i j}+\gamma Y_{i}+\delta Z_{j}+u_{i}+u_{j}
$$

where $X_{i j}$ are observation-level variables such as the similarity variables or picture position, $Y_{i}$ are picture-level variables such as the depicted person's gender and age or outdoor activity in the picture, and $Z_{j}$ are observer-level variables such as the observer's education and level of Facebook activity. The terms $u_{i}$ and $u_{j}$ are the random effects for the picture and observer, respectively.

To get further insights into the observers' biases, we estimate a second model that predicts guessing higher education with observer-level and picture-level variables only.

\section{Results}

Table 1 displays the demographics of the picture and observer samples, as compared to the general US population according to estimates based on US Census data from July 2017 (US Census Bureau 2018). Our samples are quite diverse, although compared to the general US population, we have better educated, more urban, and younger individuals and fewer Hispanics. The observers are more likely to be male and better educated than the pictured individuals, and hence tend to have higher income. The reason for this is that we intentionally balanced the picture sample on education although the AMT population tends to be better educated in general.

Figure 1 summarizes the results of the binomial test and the intercept-only cross-classified logistic random effects model testing $\mathrm{H} 1.61 .2 \%$ of the education guesses were successful, with a $95 \%$ confidence interval based on a two-sided binomial test ranging from $60.6 \%$ to $61.8 \%$. Hence, the binomial test indicates that observers can guess a person's education from their profile pictures better than chance. Controlling for the fact that observations are nested within observers and within picture pairs with a cross-classified random effects model allows us to get a more rigorous result. We estimate the overall probability of a successful guess to be $63,6 \%$ and with $95 \%$ confidence, within the interval between $58.7 \%$ and $68.2 \%$. The model reveals variance at the picture level of

\footnotetext{
${ }^{2}$ We estimated the generalized linear mixed-effects models using the $1 \mathrm{me} 4 \mathrm{R}$-package and confirmed the robustness of the results and the convergence of the model using different optimizers (Bates et al. 2015).
} 
Table 1: Demographics of the picture and the observer samples.

\begin{tabular}{|c|c|c|c|c|c|}
\hline & \multicolumn{3}{|c|}{ Pictured individuals $(n=112)$} & \multirow{2}{*}{$\begin{array}{c}\text { Observers } \\
(n=713)\end{array}$} & \multirow[t]{2}{*}{ US pop. } \\
\hline & Total & Higher edu & No higher edu & & \\
\hline Female & 0.53 & 0.50 & 0.55 & 0.45 & 0.51 \\
\hline Age (median) & 32 & 31.5 & 32.5 & 32 & 37.9 \\
\hline White & 0.79 & 0.73 & 0.84 & 0.79 & 0.77 \\
\hline Black & 0.11 & 0.11 & 0.11 & 0.10 & 0.13 \\
\hline Asian & 0.07 & $0.13^{*}$ & $0.02^{*}$ & 0.07 & 0.06 \\
\hline Hispanic & 0.06 & 0.07 & 0.05 & 0.10 & 0.18 \\
\hline No higher education ${ }^{1}$ & 0.50 & 0.00 & 1.00 & 0.40 & 0.70 \\
\hline Higher education & 0.50 & 1.00 & 0.00 & 0.60 & 0.30 \\
\hline Income (median) & $\$ 30-50 K$ & $\$ 50-70 K^{* *}$ & $\$ 30-50 K^{* *}$ & $\$ 50-70 \mathrm{~K}$ & $\$ 55 \mathrm{~K}$ \\
\hline Urban $^{2}$ & - & - & - & 0.43 & 0.13 \\
\hline Active on $\mathrm{FB}^{3}$ & 1.00 & 1.00 & 1.00 & 0.64 & 0.68 \\
\hline FB friends (median) & $151-300$ & $301-500^{*}$ & $151-300^{\star}$ & & \\
\hline Eyeglasses & 0.20 & 0.18 & 0.21 & & \\
\hline Revealing clothing & 0.02 & 0.04 & 0.01 & & \\
\hline Outdoor & 0.28 & $0.40^{\star *}$ & $0.16^{* *}$ & & \\
\hline Sport & 0.05 & 0.07 & 0.04 & & \\
\hline Professional picture & 0.05 & 0.06 & 0.04 & & \\
\hline Filter & 0.16 & 0.15 & 0.16 & & \\
\hline Selfie & 0.53 & $0.33^{* *}$ & $0.72^{* *}$ & & \\
\hline
\end{tabular}

Two-sample t-test for difference between means: ${ }^{* * *} p<0.001,{ }^{* *} p<0.01,{ }^{*} p<0.05$

${ }^{1}$ For the picture sample, we exclude individuals who have some college experience short of Bachelor's degree. For the observer sample, we include the $31.7 \%$ who are in this position in the "no higher education" category. Testing the hypotheses with observer's education operationalized as an interval variable does not substantively change the results.

2 Defined as cities with population of more than 500,000 . The statistic for the US population is sourced from https: / / www. census.gov/data/tables/2017/demo/ popest/total-cities-and-towns.html.

${ }^{3}$ Due to different scales, the number for our observer sample is not fully comparable to the US statistic (Smith and Anderson 2018). 


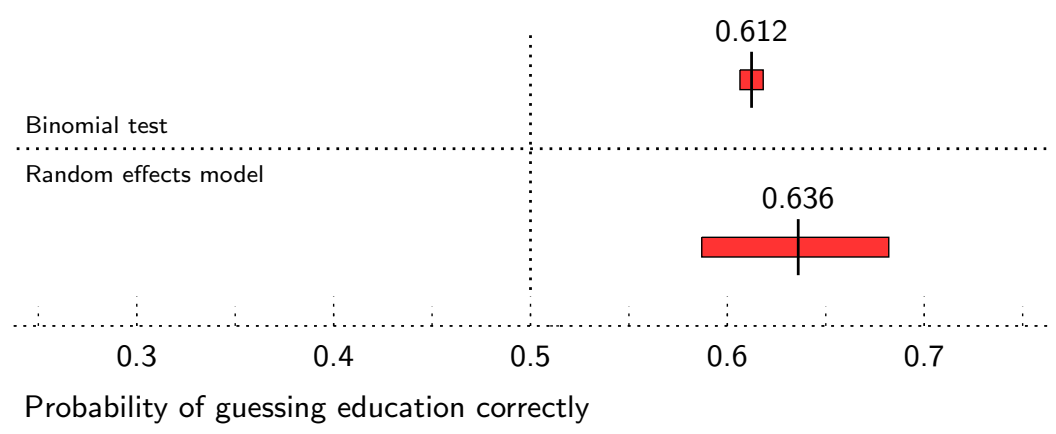

Figure 1: Mean and 95\% confidence interval for binomial test and intercept-only cross-classified logistic mixed effects model.

1.174 and variance at the observer level of 0.061 (Model A in Table 2). According to the intraclass correlation, $25.9 \%$ of the total variance in the successfulness of guesses is explained by picture variability while $1.3 \%$ is explained by observer variability. This suggests that observers are better at guessing a person's education from their profile pictures than random chance mainly because some pictures are more telling than others.

For the hypotheses on perceptiveness, we test the effect of social similarity between the observer and the observed and the effect of relevant observer characteristics on the likelihood of a correct guess (Model B in Table 2). We do not find evidence that observers who share the same age, gender, race, or ethnicity with the pictured individual are better at guessing their education. Nevertheless, we find that when the depicted person and the observer are both with or both without higher education, the odds of successfully guessing the education increase by $23.2 \%$, keeping other factors constant. This result provides partial confirmation of $\mathrm{H} 2$. The evidence for $\mathrm{H} 3$ is somewhat contradictory. In alignment with our expectations, observers who are active on Facebook are better at guessing the pictured person's education but surprisingly, having higher education and living in urban settings in fact reduces the observer's likelihood to guess correctly, significantly so in the latter case.

For the hypothesis on self-presentation, we test the effects of salient characteristics of the picture and the depicted person on whether the education guess was correct. In addition, we investigate the effects of these characteristics on whether the observer rated the depicted person as higher educated (Model C in Table 2). This allows us to differentiate between informative signals (increase success), misleading signals (decrease success), useful stereotypes (predict education guess and improve success), and misleading stereotypes (predict education guess but decrease success).

The results suggest that if the depicted person is outdoors in their profile pictures, observers are more likely to guess that they have higher education and this increases the odds of successfully guessing the education by $51 \%$, controlling for the other variables. Being outdoors is thus an informative signal. Having a profile picture that is professionally photographed, in contrast, is a misleading signal, as it decreases the odds of a successful guess by $45 \%$. However, the latter result should be taken with caution because only 11 out of 224 pictures were labeled as professionally taken. Finally, there is a tendency to assume that Asians have higher education but this stereotype does not prove 
Table 2: Results on the effects of observer perceptiveness and picture and depicted person characteristics on the likelihood of guessing education successfully (Models A-B) or guessing higher education (Model C).

\begin{tabular}{|c|c|c|c|}
\hline & A) Success & B) Success & C) Guess higher edu \\
\hline Same education & & $0.209(0.029)^{* \star *}$ & \\
\hline Same age & & $-0.015(0.036)$ & \\
\hline Same gender & & $-0.030(0.029)$ & \\
\hline Same race & & $0.046(0.058)$ & \\
\hline Same ethnicity & & $-0.165(0.091)$ & \\
\hline Observer higher education & & $-0.068(0.036)$ & $0.180(0.066)^{\star *}$ \\
\hline Observer active on FB & & $0.054(0.021)^{\star *}$ & $0.014(0.038)$ \\
\hline Observer urban & & $-0.104(0.035)^{\star *}$ & $0.250(0.065)^{\star * *}$ \\
\hline Eyeglasses & & $-0.130(0.136)$ & $0.136(0.141)$ \\
\hline Revealing clothing & & $-0.384(0.498)$ & $-0.450(0.518)$ \\
\hline Outdoor & & $0.412(0.158)^{\star \star}$ & $0.402(0.164)^{*}$ \\
\hline Sport & & $0.174(0.276)$ & $0.596(0.286)^{*}$ \\
\hline Professional picture & & $-0.603(0.296)^{*}$ & $0.143(0.306)$ \\
\hline Filter & & $-0.151(0.168)$ & $-0.290(0.174)$ \\
\hline Selfie & & $0.198(0.144)$ & $0.040(0.149)$ \\
\hline Age & & $0.011(0.013)$ & $0.023(0.013)$ \\
\hline Female & & $0.091(0.208)$ & $0.260(0.216)$ \\
\hline Black & & $0.217(0.324)$ & $-0.308(0.333)$ \\
\hline Asian & & $0.475(0.384)$ & $1.405(0.396)^{\star * *}$ \\
\hline Other race & & $0.742(0.627)$ & $0.320(0.651)$ \\
\hline Hispanic & & $-0.592(0.488)$ & $-0.914(0.503)$ \\
\hline Higher education & & $0.543(0.213)^{*}$ & $0.934(0.220)^{\star * *}$ \\
\hline Position & & $-0.004(0.001)^{* *}$ & $0.002(0.001)$ \\
\hline Intercept & $0.558(0.104)^{* * *}$ & $-0.588(0.560)$ & $-1.746(0.591)^{* *}$ \\
\hline Log Likelihood & -15068 & -15004 & -14409 \\
\hline Variance observers & 0.061 & 0.053 & 0.513 \\
\hline Variance picture pair & 1.174 & 0.900 & 0.962 \\
\hline
\end{tabular}

The table shows log odds with standard errors in parentheses from cross-classified logistic mixed effects models. Models $B-C$ additionally control for the observer's age, gender, race, ethnicity, and income. ${ }^{* * *} p<0.001,{ }^{* *} p<0.01,{ }^{*} p<0.05$. 
useful over our sample of profile pictures as it does not significantly increase the likelihood for a correct education guess. The same holds for persons doing sports in their profile pictures.

Model $\mathrm{C}$ in Table 2 also gives us an insight as to why we did not observe positive effects from observer's education and urban sophistication contrary to the expectations. It appears that higher educated observers who live in cities tend to overestimate the proportion of higher educated individuals.

Finally, Model B in Table 2 indicates that observers are more likely to guess the education of those with higher education, suggesting that perhaps these individuals send stronger signals of their habitus. Among the observers' demographics we control for, we only find statistically significant positive effect from income on the likelihood to guess education correctly $(\beta=0.025$, s.e. $=0.010, p<0.05)$. We also find a statistically significant negative effect from picture position on success. Pictures that where shown to observers closer to the end of the survey where assessed less accurately, indicating a decrease in participants' attention. ${ }^{3}$

\section{Discussion}

Our main research question was whether people can perceive someone's education based on their social media profile pictures. Results from a carefully balanced survey with a large number of participants recruited via Amazon's Mechanical Turk indicate that the answer to this question is positive. We found that $61.2 \%$ of all attempts to guess the education of a person from two of their Facebook profile pictures were successful, which is significantly more than expected by chance. We also found that some pictures are systematically easier for participants to guess correctly, while others are more difficult and even misleading. In fact, $25.9 \%$ of the total variance in guess success was due to picture variability, remarkably more than the $1.3 \%$ contribution by observer variability. This is not surprising since we imposed minimal restrictions on the picture selection, with the aim of achieving a realistic reflection of actual social media profiles. In contrast to most previous similar studies, we used the natural heterogeneity in picture features and quality as an important subject to investigate, rather than a nuisance to overcome. In photograph evaluation research, it is a common practice to crop, edit, or stage photos for analytic purposes, often resulting in a rather homogeneous selection (Valla et al. 2011; Etcoff et al. 2011; Kleisner et al. 2014; Wilson and Rule 2015; Wang and Kosinski 2018). Depending on the context this might be useful but it reduces the complexity of the depicted subject and deprives the photo of its naturalness. Consequently, this practice limits or even distorts inferences to real world settings where those pictures or the depicted persons might appear entirely differently. Cropping or editing - and, therefore, homogenizing pictures with the aim to increase internal validity - was not a sensible approach for this study in particular. Only the original profile pictures include the full set of distinct strategies and hidden clues, imposing exactly the impression on observers that was intended by the picture owner.

\footnotetext{
${ }^{3}$ Limiting the analysis to only the first 20 photos viewed by each participant does not lead to substantive changes. Most notably, the probability of guessing education correctly in Figure 1 increases from 0.612 to 0.623 in the binomial test and from 0.636 to 0.647 in the random effects model.
} 


\section{Perceptiveness}

Our study suggests that similarity in education between the observer and the depicted person and familiarity with Facebook increase the likelihood to correctly guess a person's education from their profile pictures. We assumed that it will be easier for a 25 -year-old white man to understand relevant signals of distinction of someone else like him better than the signals of distinction applied by a 70-year-old Asian woman, for example. However, we did not find evidence that similarity in age, gender, race, or ethnicity necessarily imply heightened perceptiveness of the depicted strategies of distinction. When it comes to assessing education, similarity in education is the theoretically and empirically most important and reliable key to correctly assess it. Being socialized in a similar environment (e.g. university) allows insights into norms, values, trends, traditions and implicit rules of that social field that are only disclosed to those participating. Beyond plain insights, such experiences trickle into the unconsciousness and are embodied in the habitus. Referring to Goffman, Bourdieu calls this "a sense of one's place" (Bourdieu 2000: p.184), a practical sense of one's own position and the position of others. Someone who did not attend university has, therefore, a comparatively abstract understanding of the rules and rankings of this social field. Consequentially, familiarity with the field leads to a better assessment of strategies of distinction as we demonstrate empirically.

Based on theory, we also expected that higher educated and more urban observers will be more perceptive of signals of distinction but, in fact, we found suggestive evidence to the contrary. It appears that the higher educated and the urbanites are worse at guessing another person's education because they tend to overestimate the proportion of higher educated individuals. It is true that university-educated individuals are overrepresented on AMT, but our survey did not inform participants that they are evaluating Facebook profile pictures provided by AMT users. Neither did we inform participants that our sample of profile pictures is balanced on education. Still, universityeducated individuals are overrepresented on Facebook (Smith and Anderson 2018), so it is possible that these more sophisticated observers started with a better informed prior on the distribution of education among Facebook users and extrapolated this knowledge to our sample of Facebook profile pictures. Nevertheless, it is also possible that the higher educated and the urban dwellers have a skewed perception of the prevalence of higher educated individuals. Due to homophily, we rarely experience a random sample of the social world in our daily life and hence, our expectations about others may be highly biased. Homophily is a universal social mechanism that affects everyone in terms of perception and evaluation but our study was designed in a way that placed the better educated at a disadvantage. This is a limitation of our study that future research could address.

\section{Self-presentation}

Our research further suggests that individuals who post profile pictures of themselves being outdoors successfully signal their higher education while individuals who select professionally taken photographs successfully obscure this information. Both effects are relatively strong - stronger than the effect of similarity in education, for example. 
Observers are more likely to identify a person pictured in the outdoors as higher educated and this is often the correct answer because indeed, those with higher education have more outdoors profile pictures on average. One explanation for this finding could be that outdoors pictures depict physically strenuous leisurely activities, appreciation of nature, or cultural tourism - cultural markers for the higher educated. An alternative explanation would be that outdoors pictures contain economic markers associated with higher education. Especially compared to an indoor selfie shot, the amount of information in an outdoor picture is higher, potentially showing international touristic sights, new cars, expensive hobbies, etc. In supplementary analyses, we attempted to identify the mechanisms more precisely, by distinguishing between pictures taken outdoors in extraordinary or vacation settings and outdoor pictures of hiking, in addition to pictures showing activity and context in general, in contrast to shots with non-informative backgrounds. ${ }^{4}$ Unfortunately, none of these features appeared to play a significant role, suggesting that either we are failing to capture other more important signals or we need larger data to explore such fine nuances. It is, therefore, promising for future research to investigate more closely which features in an outdoor setting are decisive and picked up as an educational clue.

A professional picture does not affect the observer's education guess systematically but decreases their likelihood to be successful in guessing. In contrast, observers systematically rate Asian people and people doing sports in their profile pictures as more likely to have higher education but these are not useful biases for our picture sample as they do not improve guessing success. These results are in line with the American stereotype and myth on Asian Americans being 'smart' and educationally 'successful' (Hurh and Kim 1989; Thompson et al. 2016). Interestingly, although significantly more prevalent in the profile pictures of people without higher education, selfie shots were not taken as a hint for education and did not influence the guessing success. No other coded feature showed a significant effect on the likelihood to guess higher education or to be successful with one's guess. This, of course, could be due to the relatively small picture sample we had and it is possible that a larger-scale study could detect evidence for other picture features. A larger set of pictures would also allow to test for the omnivore thesis (Peterson 1992), which, in this context, leads us to expect a more diverse and eclectic self-presentation by the higher educated.

Our study relied on a small number of manually coded picture features compared to other studies using algorithmic tools for picture tagging (Liu et al. 2016; Segalin et al. 2017). As an alternative or a supplement to manual coding, automatized feature detection can increase the number of coded features. Additional classification could be applied for emotions of people, brightness, color diversity and temperature, size and format of the image, and others, many of which address subtle aspects of how rather than what is captured in a picture. The observed effect of professional pictures - pictures with good illumination, sharpness, and depth - suggest that such aspects are taken up by the observer. Indeed, it is plausible that alongside (or instead of) manifest signals, latent and subtle aspects of the picture like the atmosphere or the overall composition influence the assessment of the observer, maybe even unconsciously.

\footnotetext{
${ }^{4}$ These additional analyses are available from the authors upon request.
} 
Additionally, body and facial traits such as physical attractiveness and body mass index (BMI) could be considered. Impressions of attractiveness and BMI have been shown to influence many attributed characteristics such as competence, professional success, or laziness (Puhl and Heuer 2009; Etcoff et al. 2011; Kuipers 2015). Since obesity is more prevalent among low educated people in the US (Cohen et al. 2013), it is expected to affect people's judgement of others' education.

\section{Conclusion}

Inspired by the Bourdieusian concepts of habitus and distinction, our study aimed to increase our understanding of self-expression and social interaction on social media, two phenomena with increasing societal relevance. Specifically, our focus was on whether people can perceive education based on social media profile pictures. We found that, on average, observers perceive education from profile pictures better than chance. The fact that observers are better at guessing the education of similarly educated others supports Bourdieu's idea that some strategies of distinction are subtle, only visible to those in the know. But in contradiction to Bourdieu, the fact that urban dwellers and those with higher education excessively ascribe higher education to others suggests that habitus and social environment could cloud people's reading of each other. Finally, we identified specific strategies that are surprisingly informative (being pictured outdoors) or misleading (relying on professional photography), providing concrete insights on how habitus is communicated online.

Our focus on perception and interaction introduces an important new angle to the current literature on the evaluation and analysis of personal photographs. There has been a growing interest in the application of machine learning algorithms in the context of picture and face analysis for social science research questions (Liu et al. 2016; Segalin et al. 2017; Wang and Kosinski 2018). These methods, however, do not take into consideration the fact that sharing and viewing a personal photograph constitute a social interaction. Our contribution is to disentangle this social interaction between the observer and the person in the profile picture in terms of what each of the two actors contribute independently and together as a dyad. Current machine learning algorithms are not designed to address interaction or situations that are interpreted or perceived differently by different observers. This presents a potential area for development for artificial intelligence.

The main limitation of our study lies in its limited external validity. Samples based on AMT - this one included - have proven to be diverse but they do not allow for inferences on the Facebook population or society in general. Moreover, the picture sample of this study was limited to Facebook, the world's most popular social media platform. Although Bourdieu's theory of habitus and distinction is not limited to Facebook users only, it is probable that strategies of distinction and other aspects of habitus are manifested differently on other platforms. Further research could, therefore, integrate other platforms in the investigation as well.

There are a number of possible avenues to build on and extend the findings of this work. Qualitative research with focus groups and in-depth interviews could lead to additional insights into how social media users apply strategies of distinction and how they perceive pictures of others. Alongside 
the value of the findings themselves, such insights could indicate additional picture features for quantitative analysis. Subjective features such as physical attractiveness and fitness could be coded via crowdsourcing, relying on the wisdom of the crowd. Additional features of the pictures might be coded also with the help of deep learning techniques. Generally, it can be tested whether such algorithms are capable of assessing persons' education or social status just based on profile pictures. Doing so would help scholars gain important insights and knowledge on novel techniques that social media platform providers probably already apply.

It is also important not to forget that pictures are only one component of a person's Facebook profile. The user name, profile text, declared group memberships, or followed accounts, for example, also contribute to the online image. A multi-modal analysis would take these other elements and their interplay into account and produce a more realistic and complex evaluation than the isolated examination of pictures we did here. Such holistic analysis of the construction and presentation of self on social media could then also reflect on the social environment of the picture and investigate the discursive social frames and narrative meanings attached to it (Kress and Van Leeuwen 2006; Davies 2007).

Our finding that a person's profile picture can act as a valuable signal of their education and habitus carries implications for the study of social interaction and influence online. Profile pictures might influence individuals' social capital in terms of who interacts with whom and thus mold the social structure of social media communities generally. Profile pictures might also affect who pays attention to whom and thus contribute to the viral spread of information on these communities. Further research could therefore evaluate these links. For example, one promising direction is to investigate experimentally the propensity of users to read, like, or share news articles depending on the profile picture of the stranger who posts them and the similarity between that person's signaled education and one's own.

Overall, our work demonstrates the continuing value and predictive power of Bourdieu's theory for the empirical investigation of complex social relations. We see great promise in research that applies Bourdieusian thinking to the context of social media and revives cultural sociology under this perspective.

\section{References}

Agüera y Arcas, B., Todorov, A., and Mitchell, M. (2018). Do algorithms reveal sexual orientation or just expose our stereotypes? Available at: https : / / medium . com / @blaisea / do-algorithms - reveal - sexual - orientation-or - just - expose - our stereotypes-d998fafdf 477 (accessed 4 July 2019).

Ambady, N. and Rosenthal, R. (1992). Thin Slices of Expressive Behavior as Predictors of Interpersonal Consequences: A Meta-Analysis. Psychological Bulletin 111.2, 256-274.

Baert, S. (Mar. 2018). Facebook profile picture appearance affects recruiters' first hiring decisions. New Media \& Society 20.3, 1220-1239. 
Bates, D., Mächler, M., Bolker, B. M., and Walker, S. C. (2015). Fitting Linear Mixed-Effects Models Using lme4. Journal of Statistical Software 67.1, 1-48.

Büchi, M., Just, N., and Latzer, M. (2016). Modeling the second-level digital divide: A five-country study of social differences in Internet use. New Media \& Society 18.11, 2703-2722.

Berger, P. L. and Luckmann, T. (1991). The Social Construction of Reality: A Treatise in the Sociology of Knowledge. London: Penguin.

Bourdieu, P. (1974). "The school as a conservative force: scholastic and cultural inequalities". In: Contemporary Research in the Sociology of Education. Eggleston, J. (ed.). Oxon and New York: Routledge, 32-46.

Bourdieu, P. (1977). Outline of a Theory of Practice. Cambridge: Cambridge University Press.

Bourdieu, P. (1984). Distinction. A Social Critique of the Judgement of Taste. Cambridge: Harvard University Press.

Bourdieu, P. (1986). “The Forms of Capital”. In: Handbook of Theory and Research for the Sociology of Education. Richardson, J. (ed.). Westport, CT: Greenwood, 241-258.

Bourdieu, P. (1990). The Logic of Practice. Cambridge: Polity Press.

Bourdieu, P. (2000). Pascalian Meditations. Stanford: Stanford University Press.

Buhrmester, M. D., Talaifar, S., and Gosling, S. D. (2018). An Evaluation of Amazon's Mechanical Turk, Its Rapid Rise, and Its Effective Use. Perspectives on Psychological Science 13.2, 149154.

Casler, K., Bickel, L., and Hackett, E. (2013). Separate but equal? A comparison of participants and data gathered via Amazon's MTurk, social media, and face-to-face behavioral testing. Computers in Human Behavior 29, 2156-2160.

Cialdini, R. B. (2007). Influence: The Psychology of Persuasion. New York: HarperBusiness.

Cohen, A. K., Rai, M., Rehkopf, D. H., and Abrams, B. (2013). Educational attainment and obesity: a systematic review. Obesity Reviews 14.12, 989-1005.

Correll, S. J. and Ridgeway, C. L. (2003). "Expectation states theory". In: Handbook of Social Psychology. Delamater, J. (ed.). Springer, 29-51.

Daniels, E. A. and Zurbriggen, E. L. (2016). The Price of Sexy: Viewers' Perceptions of a Sexualized Versus Nonsexualized Facebook Profile Photograph. Psychology of Popular Media Culture 5.1, $2-14$.

Davies, J. (2007). Display, Identity and the Everyday: Self-presentation through online image sharing. Discourse: Studies in the Cultural Politics of Education 28.4, 549-564.

Difallah, D., Filatova, E., and Ispeirotis, P. (2018). "Demographics and Dynamics of Mechanical Turk Workers”. In: Proceedings of the Eleventh ACM International Conference on Web Search and Data Mining.

Dumais, S. A. (2002). Cultural Capital, Gender, and School Success: The Role of Habitus. Sociology of Education 75.1, 44.

Etcoff, N. L., Stock, S., Haley, L. E., Vickery, S. A., and House, D. M. (2011). Cosmetics as a Feature of the Extended Human Phenotype: Modulation of the Perception of Biologically Important Facial Signals. PLoS ONE 6.10.

Facebook (2019). Company Statistics. Available at: https : / / news room. fb . com/ companyinfo/. 
Gleibs, I. H. (2017). Are all "research fields" equal? Rethinking practice for the use of data from crowdsourcing market places. Behavior Research Methods 49, 1333-1342.

Goffman, E. (1956). The Presentation of Self in Everyday Life. Edinburgh: University of Edinburgh.

Gray, K., Knobe, J., Sheskin, M., Bloom, P., and Feldman Barrett, L. (2011). More than a Body: Mind Perception and the Nature of Objectification. Journal of Personality and Social Psychology 101.6, 1207-1220.

Hancock, J. and Toma, C. L. (2009). Putting Your Best Face Forward: The Accuracy of Online Dating Photographs. Journal of Communication 59, 367-386.

Hara, K., Adams, A., Milland, K., Savage, S., Callison-Burch, C., and Bigham, J. P. (2018). “A Data-Driven Analysis of Workers' Earnings on Amazon Mechanical Turk”. In: Proceedings of the 2018 CHI Conference on Human Factors in Computing Systems. ACM, 449.

Hargittai, E. and Hinnant, A. (2008). Digital Inequality: Differences in Young Adult's Use of the Internet. Communication Research 35.5, 602-621.

Haselhuhn, M. P. and Wong, E. M. (2011). Bad to the bone: facial structure predicts unethical behaviour. Proceedings of the Royal Society B: Biological Sciences 279.1728, 571-576.

Hetsroni, A. and Guldin, D. A. (2017). Revealing Images as Facebook Profile Pictures: Influences of Demographics and Relationship Status. Social Behavior and Personality 45.6, 987-998.

Holt, D. B. (1998). Does Cultural Capital Structure American Consumption? Journal of Consumer Research 25.1, 1-25.

Horvat, E. M. and Davis, J. E. (2011). Schools as Sites for Transformation: Exploring the Contribution of Habitus. Youth \& Society 43.1, 142-170.

Hum, N. J., Chamberlin, P., Hambright, B. L., Portwood, A., Schat, A., and Bevan, J. (2011). A picture is worth a thousand words: A content analysis of Facebook profile photographs. Computers in Human Behavior 27, 1828-1833.

Hurh, W. M. and Kim, K. C. (1989). The 'success' image of Asian Americans: Its validity, and its practical and theoretical implications. Ethnic and Racial Studies 12.4, 512-538.

Johnston, J. and Baumann, S. (2007). Democracy versus Distinction: A Study of Omnivorousness in Gourmet Food Writing. American Journal of Sociology 113.1, 165-204.

Junco, R. (2013). Inequalities in Facebook use. Computers in Human Behavior 29, 2328-2336.

Kapidzic, S. (2013). Narcissism as a Predictor of Motivations Behind Facebook Profile Picture Selection. Cyberpsychology, Behavior, and Social Networking 16.1, 14-19.

Kapidzic, S. and Herring, S. C. (2015). Race, gender, and self-presentation in teen profile photographs. New Media \& Society 17.6, 958-976.

Kleisner, K., Chvátalová, V., and Flegr, J. (2014). Perceived Intelligence Is Associated with Measured Intelligence in Men but Not Women. PLOS One 9.3. Fink, B. (ed.), e81237.

Kress, G. and Van Leeuwen, T. (2006). Reading Images: The Grammar of Visual Design. Oxon and New York: Taylor \& Francis Ltd.

Krippendorff, K. (2004). Content Analysis. Thousand Oaks: SAGE.

Kuipers, G. (2015). Beauty and distinction? The evaluation of appearance and cultural capital in five European countries. Poetics 53, 38-51.

Lawson, C., Lenz, G. S., Baker, A., and Myers, M. (2010). Looking Like a Winner: Candidate Appearance and Electoral Success in New Democracies. World Politics 62.04, 561-593. 
Leder, H., Forster, M., and Gerger, G. (2011). The Glasses Stereotype Revisited. Effects of Eyeglasses on Perception, Recognition, and Impression of Faces. Swiss Journal of Psychology 70.4, 211-222.

Lehmann, W. (2013). Habitus Transformation and Hidden Injuries. Sociology of Education 87.1, $1-15$.

Lin, C., Adolphs, R., and Alvarez, R. M. (2018). Inferring whether officials are corruptible from looking at their faces. Psychological Science, 1-18.

Liu, H. (2008). Social Network Profiles as Taste Performances. Journal of Computer-Mediated Communication 13, 252-275.

Liu, L., Preotiuc-Pietro, D., Samani, Z. R., Moghaddam, M. E., and Ungar, L. (2016). "Analyzing Personality through Social Media Profile Picture Choice". In: Tenth International AAAI Conference on Web and Social Media, 211-220.

Lutz, C. (2016). A Social Milieu Approach to the Online Participation Divides in Germany. Social Media + Society, 1-14.

McPherson, M., Smith-Lovin, L., and Cook, J. M. (2001). Birds of a feather: Homophily in social networks. Annual Review of Sociology 27.1, 415-444.

Oosterhof, N. N. and Todorov, A. (2008). The functional basis of face evaluation. Proceedings of the National Academy of Sciences 105.32, 11087-11092.

Peterson, R. A. (1992). Understanding audience segmentation: From elite and mass to omnivore and univore. Poetics 25, 75-92.

Pfeil, U., Arjan, R., and Zaphiris, P. (2009). Age differences in online social networking - A study of user profiles and the social capital divide among teenagers and older users in MySpace. Computers in Human Behavior 25, 643-654.

Puhl, R. M. and Heuer, C. A. (2009). The Stigma of Obesity: A Review and Update. Obesity 17.5, 941-964.

Qiu, L., Lu, J., Yang, S., Qu, W., and Zhu, T. (2015). What does your selfie say about you? Computers in Human Behavior 52, 443-449.

Robinson, L. (2009). A Taste for the Necessary. Information, Communication \& Society 12.4, 488-507.

Rogers, E. M. (2010). Diffusion of Innovations. New York: Simon and Schuster.

Rule, N. O. and Ambady, N. (Jan. 2010). Democrats and republicans can be differentiated from their faces. PLOS ONE 5.1, e8733.

Segalin, C., Celli, F., Polonio, L., Kosinski, M., Stillwell, D., Sebe, N., Cristani, M., and Lepri, B. (2017). "What your Facebook profile picture reveals about your personality". In: Proceedings of the 2017 ACM on Multimedia Conference. ACM, 460-468.

Smith, A. and Anderson, M. (2018). Social media use in 2018. Available at: http : / / www . pewinternet.org/2018/03/01/social-media-use-in-2018/.

Strano, M. M. (2008). User Descriptions and Interpretations of Self-Presentation through Facebook Profile Images. Journal of Psychological Research on Cyberspace 2.2, 5.

Thompson, T. L., Kiang, L., and Witkow, M. R. (2016). "You're Asian: You're supposed to be smart": Adolescents' experiences with the Model Minority Stereotype and longitudinal links with identity. Asian American Journal of Psychology 7.2, 108-119. 
Todorov, A. and Porter, J. M. (2014). Misleading First Impressions: Different for Different Facial Images of the Same Person. Psychological Science 25.7, 1404-1417.

Todorov, A., Mandisodza, A. N., Goren, A., and Hall, C. C. (2005). Inferences of Competence from Faces Predict Election Outcomes. Science 308, 1623-1626.

Todorov, A., Oliviola, C. Y., Dotsch, R., and Mende-Siedlecki, P. (2015). Social Attributions from Faces: Determinants, Consequences, Accuracy, and Functional Significance. Annual Reveiw of Psychology 66, 519-545.

Turcotte, J., York, C., Irving, J., Scholl, R. M., and Pingree, R. J. (2015). News Recommendations from Social Media Opinion Leaders: Effects on Media Trust and Information Seeking. Journal of Computer-Mediated Communication 20.5, 520-535.

US Census Bureau (2018). QuickFacts United States. Available at: http: / / www . pewinternet . org/2018/03/01/social-media-use-in-2018/.

Valla, J. M., Ceci, S. J., and Williams, W. M. (2011). The Accuracy of Inferences about Criminality based on Facial Appearance. Journal of Social, Evolutionary and Cultural Psychology 5.1, 66-91.

Van Dijck, J. (2008). Digital photography: communication, identity, memory. Visual Communication $7.1,57-76$.

Veblen, T. (2007 [1899]). The Theory of the Leisure Class. Oxford: Oxford University Press.

Wang, R., Yang, F., and Haigh, M. M. (2017). Let me take a selfie: Exploring the psychological effects of posting and viewing selfies and groupies on social media. Telematics and Informatics 34.4, 274-283.

Wang, Y. and Kosinski, M. (2018). Deep neural networks are more accurate than humans at detecting sexual orientation from facial images. Journal of Personality and Social Psychology 114.2, $246-257$.

Ward, J. (2017). What are you doing on Tinder? Impression management on a matchmaking mobile app. Communication \& Society 20.11, 1644-1659.

West, E. (2010). A taste for greeting cards: Distinction within a denigrated cultural form. Journal of Consumer Culture 10.3, 362-382.

Wilson, J. P. and Rule, N. O. (2015). Facial Trustworthiness Predicts Extreme Criminal-Sentencing Outcomes. Psychological Science 26.8, 1325-1331.

Winston, J. (2013). Photography in the Age of Facebook. Intersect 6, 1-11.

Wu, Y.-C. J., Chang, W.-H., and Yuan, C.-H. (2015). Do Facebook profile pictures reflect user's personality? Computers in Human Behavior 51, 880-889.

Yates, S. and Lockley, E. (2018). Social Media and Social Class. American Behavioral Scientist 62.9, 1291-1316.

Zebrowitz, L. A. and Montepare, J. M. (2008). Social psychological face perception: Why appearance matters. Social and Personality Psychology Compass 2.3, 1497-1517.

Zhao, S., Grasmuck, S., and Martin, J. (2008). Identity construction on Facebook: Digital empowerment in anchored relationships. Computers in Human Behavior 24, 1816-1836.

Zillien, N. and Hargittai, E. (2009). Digital Distinction: Status-Specific Types of Internet Usage. Social Science Quarterly 90.2, 274-291. 